\title{
Finite Element Models and Numerical Analysis of a Structural Glass Beam Reinforced with Embedded Carbon Fibre Rod
}

\author{
Dora Foti \\ Dept. of Sciences of Civil Engineering and Architecture \\ Polytechnic University of Bari \\ Bari, Italy \\ dora.foti@poliba.it \\ Leonarda Carnimeo \\ Dept. of Electrical \& Information Engineering \\ Polytechnic University of Bari \\ Bari, Italy \\ leonarda.carnimeo@poliba.it
}

\author{
Michela Lerna \\ Dept. of Sciences of Civil Engineering and Architecture \\ Polytechnic University of Bari \\ Bari, Italy \\ michela.lerna@poliba.it
}

\author{
Vitantonio Vacca \\ CNR-IGAG \\ Rome, Italy \\ vitantonio.vacca@igag.cnr.it
}

Received: September 23, 2019. Revised: November 10, 2019. 2nd Revised: October 1, 2020.

Accepted: October 12, 2020. Published: October 16, 2020.

\begin{abstract}
Due to the its brittleness and unpredictable failure behaviour, the glass is considered a structurally unsafe material. The poor tensile strength and the occurrence of brittle failures prevent the possible use of structural glass elements (i.e. floors, beams and columns). The present study focuses on the numerical analysis of glass beams reinforced with composite material (Fiber Reinforced Polymer) and the numerical analysis of the behaviour of glass plates after being punched. In particular, the method of reinforcement analysed consists in embedding the Carbon FRP-rod in the interlayer of laminated structural glass beams with the aim to increase their failure strength, but also the post-failure strength and ductility. A numerical analysis on different specimens has been carried out to evaluate the effect of the reinforcement. The response of the reinforced and un-reinforced beams has been compared and the results have been discussed. The results provide an estimation of the expected performance in order to propose a reinforcement method for glass beams using FRP composites. This study includes the numerical analysis on laminated glass plates with wide holes at both ends, the latter made for technological reasons to connect the glass beam to the structure. The obtained results are compared with integer specimens.
\end{abstract}

Keywords - FEM analysis, structural glass, reinforced glass beam, glass plate, CFRP-rod

\section{INTRODUCTION}

In the last years the necessity to realize buildings utilizing transparent load-bearing elements is increased considerably. In fact, constructions with transparent and translucent structural components have an excellent aesthetic value. The structural glass is the material which perfectly responds to these requirements. As it is well known, glass is characterised by a brittle behaviour and furthermore, its strength tends to decrease in the time as a result of surface damage [1]. The brittleness of this material makes quite problematic the use of glass monolithic panels. For this reason, more glass layers are bound together through interlayers in polymeric material that allow to maintain the fragments after a glass failure, so avoiding sudden collapses (fail-safe response). To prevent from the dangerous effect of a possible glass brittle failure, laminated safety glass usually made with a plastic interlayer is used to replace the monolithic glass and designed to meet expected performances [2].
As a result of its mechanical characteristics, laminated glass is being used to an increasing extent in the field of architectural glazing. In this context, an architectural laminate is defined as comprising two glass layers of arbitrary thickness together with an adhesive plastic interlayer, typically of elastomeric polymer called polyvinyl butyral (PVB). The PVB-layer keeps the fragments of broken glass plate in the frame of the glass unit after the failure and makes them safe. The elastic modulus of the PVB-material is very small if compared to the glass one (stiff glass and a soft interlayer). The lower stiffness of the central layer and the difference between in-plane displacements of the faces in contact induce an important transverse shear in the viscoelastic layer that produces a damping effect.

Moreover, the interlayer is not able to provide sufficient ductility during failure. To overcome this undesired failure behaviour, efforts have been made to introduce ductility by including other materials in the element's section, creating hybrid glass beams. Such hybrids possess post-failure (i.e. after glass failure) capacity and ductility, which result in an increased structural safety. For the case of composite glass beams (reinforced with FRP), the goal is to increase the postfailure strength and ductility by combining the high compressive strength and transparency of glass with the tensile resistance and/or ductile behaviour of the composite material [3]. A number of relevant studies on the structural performance of architectural reinforced laminated glass elements have been experimentally and numerically performed [4]-[8]. In particular, the present paper addresses the reinforcement concept utilizing composite material and focuses on laminated glass beams reinforced with carbon rods.

The glass components are applied as architectural and structural elements in buildings. In order to ensure the connection between the structural glass beams and the support structure, point-fixings (i.e. holes) are needed for the bolted connections. In the design of high load bearing elements made of glass, connections cannot be avoided in presence of large spans. For this reason, it results interesting to study the behaviour in terms of stress concentration in the area of the holes. In this regard, limited results have been obtained in other research investigations [9],[10]. 


\section{NUMERICAL STUDY}

In the field of fail-safe design, it is possible to reinforce the float glass beams with materials characterized by high tensile strength to limit or completely cancel out the negative brittle effects of glass. In particular, by including steel or composite material (i.e. FRP), it is possible to realize elements with the same bending strength. The behaviour of a glass beam reinforced with FRP-rod is similar to that of reinforced concrete beams. In fact, when the load produces the craking of the glass, the tensile stresses can be absorbed by the FRP-component, while the glass continues to support the compression stresses. In this way, it is possible to take full advantage of the high tensile strength of the reinforcement and to preserve the transparency of the beam.

The present research is intended to investigate the behaviour of the structural glass beams by embedding a Carbon FRP-rod as a reinforcement. In this regard, a numerical modelling is carried out on the reinforced and unreinforced float glass beams. The analyses were conducted on laminated beams under a load acting parallel and orthogonal to the lamination plane. Moreover, in the application of laminate glass beams it is frequently necessary to realize the holes for the connection housing with other elements. Different ways of fixing glass panels (i.e. metallic frames, structural silicone adhesives) are available, but the point-fixing of the panels through metallic supports results an efficient available technology. Therefore, the numerical study also concerns the analysis of stress concentration in the glass beams with holes when the load is applied orthogonally to the lamination plane (out-of-plane loading).

\section{Materials}

In the following sections the materials and geometry used in the beam model are discussed. The specimens are made of three glass sheets with a $10 \mathrm{~mm}$ standard thicknesses. They are held in place by an interlayer of PVB-material between the three layers of glass. The interlayer keeps the layers of the glass bonded even when broken. Ordinary float glass has been applied to all specimens. The outside glass sheet has a length greater than the internal glass sheet, so as to allow lodging of the CFRP-bar for the reinforced specimen.

The laminated glass stiffness is the result of two materials' combination (glass and PVB) with different modulus of elasticity. It is possible to modelling a laminated glass element determining an equivalent thickness of the beam that considers the mechanic characteristics of each component.

The equivalent thickness of laminated glass composed of three plies of the same thickness has been calculated in according to Timmel et al. [11], in order to consider an equivalent thickness $\mathrm{tE}$ for the plates. By assuming that a full bonding occurs between the glass and PVB interlayer because of the loading, and considering a laminated glass with Young's moduli $\mathrm{E}_{\mathrm{G}}, \mathrm{E}_{\mathrm{PVB}}$ and a total thickness of $\mathrm{t}=$ $3 t_{\mathrm{G}}+2 t_{\mathrm{PVB}}$, the required equivalent thickness results:

$$
t_{E}=\sqrt[3]{t_{G}^{3}+3 t_{G}\left(t_{G}+t_{P V B}\right)^{2}+\frac{E_{P V B}}{3 E_{G}} t_{P V B}^{3}}
$$

The properties of the adopted materials (glass and carbon rods) are listed in Table 1 . The equivalent thickness $t_{\mathrm{E}}$ is equal to $16.6 \mathrm{~mm}$.
TABLE 1. MATERIAL PROPERTIES OF GLASS AND CFRP USED IN THE FEMODELLING.

\begin{tabular}{cccc}
\hline & & Glass & CFRP \\
\hline Density & {$\left[\mathrm{Kg} / \mathrm{m}^{3}\right]$} & 2500 & 1619 \\
\hline Elastic modulus & {$\left[\mathrm{N} / \mathrm{mm}^{2}\right]$} & $70 \times 10^{3}$ & $218 \times$ \\
$10^{3}$ \\
\hline Poisson's ratio & {$[-]$} & 0.22 & 0.3 \\
\hline Tensile strength & {$\left[\mathrm{N} / \mathrm{mm}^{2}\right]$} & 45 & 2780 \\
\hline Compression strength & {$\left[\mathrm{N} / \mathrm{mm}^{2}\right]$} & 221 & - \\
\hline $\begin{array}{c}\text { Coefficient of thermal } \\
\text { expansion }\end{array}$ & {$\left[\mathrm{K}^{-1}\right]$} & $9 \times 10^{-6}$ & - \\
\hline
\end{tabular}

Figure 1a shows the stress-strain diagram of a glass type utilized for the non-linear behaviour of the beams. Similarly, in Figure $1 b$ the stress-strain diagram of the CFRP-rod used as reinforcement of beam is reported.

a)

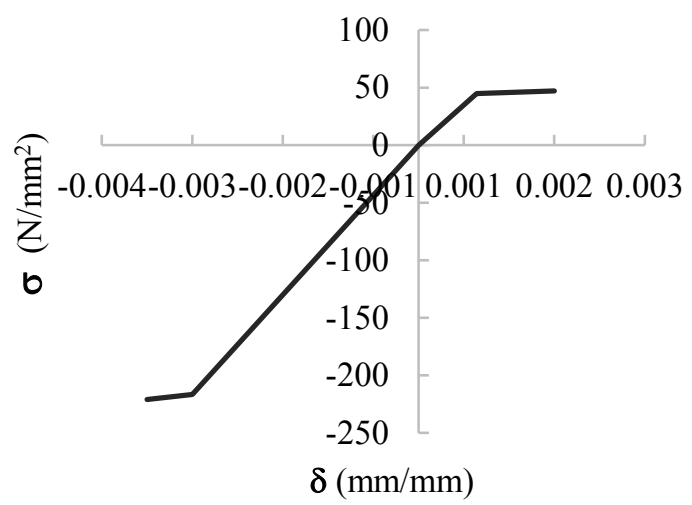

b)

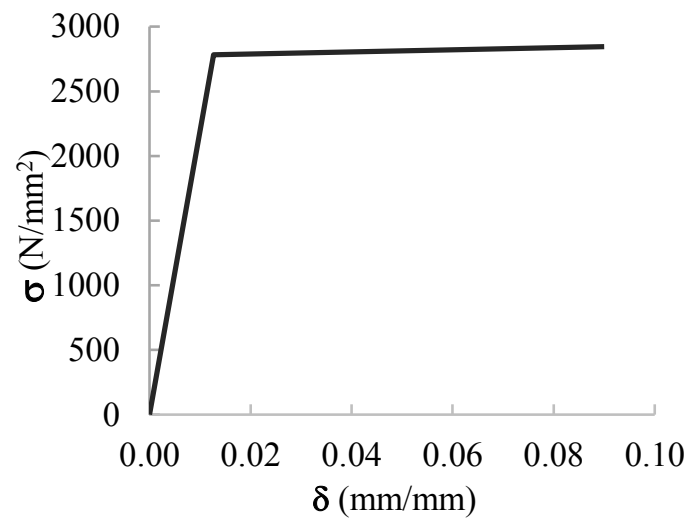

Fig.1: a) Stress-strain relationship diagram of glass; b) Stress-strain relationship diagram of CFRP.

It must be specified that the material utilized for the specimens is tempered glass. The ultimate stress for the tempered glass was determined in accordance to prEN 13474-3 (2007). In particular, the allowable stress of prestressed glass material, whichever composition is:

$$
f_{g ; d}=\frac{k_{\text {mod }} k_{s p} f_{g ; k}}{\gamma_{M ; A}}+\frac{k_{v}\left(f_{b ; k}-f_{g ; k}\right)}{\gamma_{M ; v}}
$$

where: 
- $f_{g, k}$ is the characteristic value of the bending strength $\left(\mathrm{f}_{\mathrm{g} ; \mathrm{k}}=45 \mathrm{~N} / \mathrm{mm}^{2}\right)$;

- $\gamma_{M ; A}$ is the material partial factor for tempered glass $\left(\gamma_{M ; A}=1.8\right)$;

- $k_{s p}$ is the factor for the glass surface profile $\left(k_{s p}=1\right.$ for float glass);

- $k_{\text {mod }}$ is the factor for the load duration $\left(k_{\text {mod }}=0.57\right.$ for the action of daily temperature variation with 11 hours extreme peak duration);

- $\gamma_{M ; V}$ is the material partial factor for surface prestress $\left(\gamma_{M ; V}=1.2\right)$;

- $f_{b ; k}$ is the characteristic value of the bending strength of prestressed glass $\left(f_{b ; k}=120 \mathrm{~N} / \mathrm{mm}^{2}\right.$ for thermally toughened safety glass);

- $k_{v}$ is the factor for strengthening of prestressed glass $\left(k_{v}=1\right)$.

The tensile strength of the prestressed glass is $f_{g ; d}=72$ $\mathrm{N} / \mathrm{mm}^{2}$.

\section{FE Modelling}

The analysis of the glass beams behaviour has required a detailed study of several load-patterns. For this reason, the glass beam has been modelled by considering the load applied in the lamination plane (sheet-configuration) and orthogonal to the lamination plane (plate-configuration). The typologies of the specimens investigated in this research is the following:

- Unreinforced laminated glass sheet;

- CFRP laminated glass sheet;

- Laminated glass plate;

- Laminated glass plate with holes.

In order to analyse the behaviour in the different cases, four beams with equivalent thickness and identical dimensions $(0.3 \times 3.0 \mathrm{~m})$ have been considered. Two concentred loads $(22 \mathrm{kN})$ have been applied at the third and at the two-third points of the span as shows in Figure 2. Under these load conditions, the ultimate stress value, as well as its ultimate displacement have been evaluated in the beam configuration for un-reinforced (Figure 2a) and reinforced (Figure 2b) cases.

a)
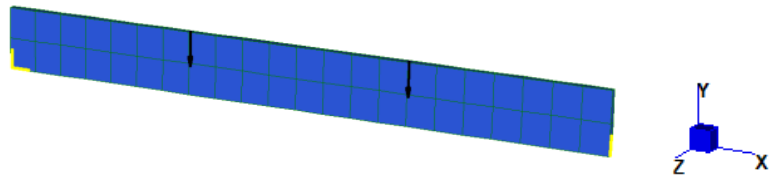

b)

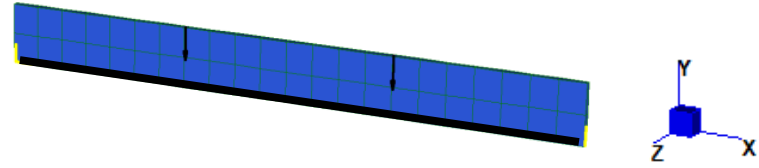

Fig. 2: Numerical model: a) Un-reinforced laminated glass sheet; b) Reinforced laminated glass sheet.

The aim of this study is to evaluate the behaviour of unreinforced beams and beams reinforced with CFRP-rod. Moreover, the influence on the structural response of a plate in the presence of holes that cross the laminated glass section has been evaluated.
The stress distribution and the ultimate displacement are evaluated in the case of plate with and without holes (holes diameter $\mathrm{d}=55 \mathrm{~mm}$ ). In the case of plate without holes, a distributed load equal to $24 \mathrm{daN} / \mathrm{cm}^{2}$ has been applied at the third and at the two-third points of the plate as shown in Figure 3a. A vertical displacement equal to $103 \mathrm{~mm}$, instead, has been applied at the third and at the two-third points (Figure $3 b$ ) of the plate with holes.

a)

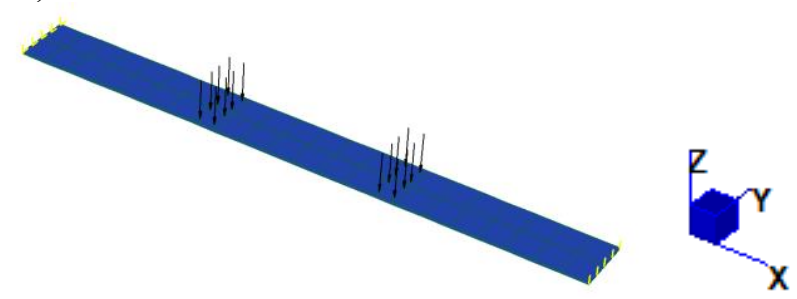

b)

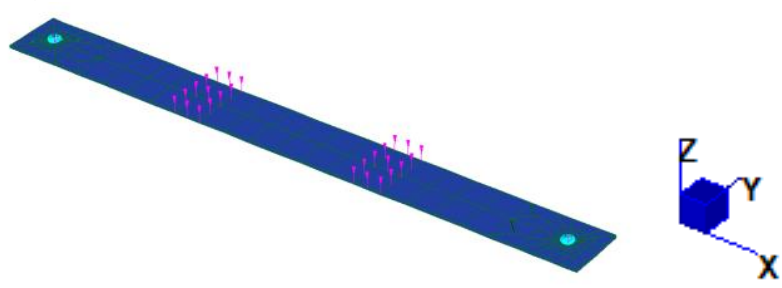

Fig. 3: Numerical Model: a) Laminated glass plate; b) Laminated glass plate with holes.

To this aim, the linear and non-linear analyses have been carried out to provide the overall response of the loaded element and to verify the flexural behaviour of the beams. The numerical simulations of the 4-point static bending test of the composite sandwich beams have been carried out using a Finite Element Model (FEM) by mean of a commercial software (STRAUS 7). The skin and the core material were modelled as 8-noded layered solid plate elements with the mechanical properties previously described. The FEM-analysis was carried out modelling the specimen and the loading set-up.

\section{Results FEM analysis}

The linear and non-linear analyses have been conducted for the sheet configuration (un-reinforced and reinforced) and for the plate configuration (without and with holes).

Figure 4 shows the distribution of the maximum stresses in the different materials both without reinforcing (Fig. 4a) and with CFRP-reinforced (Fig. 4b) glass beam. It is observed how the effect of the reinforcement redistributes the levels of stresses with a decrease of the maximum displacement in the CFRP- beam.

A different stress distribution in the several specimens results from the non-linear analysis conducted.

In particular, the curves in Figure 5 show the values of the displacement referred to each step during the analysis. It is possible to note that the slope curve of the un-reinforced beam increases significantly for the vertical displacement. The variation of the curve slope in the FRP-specimen occurs after step 13 (stress level equal to the glass tensile strength as shown in Figure 6) (see also Table 1). 
a)

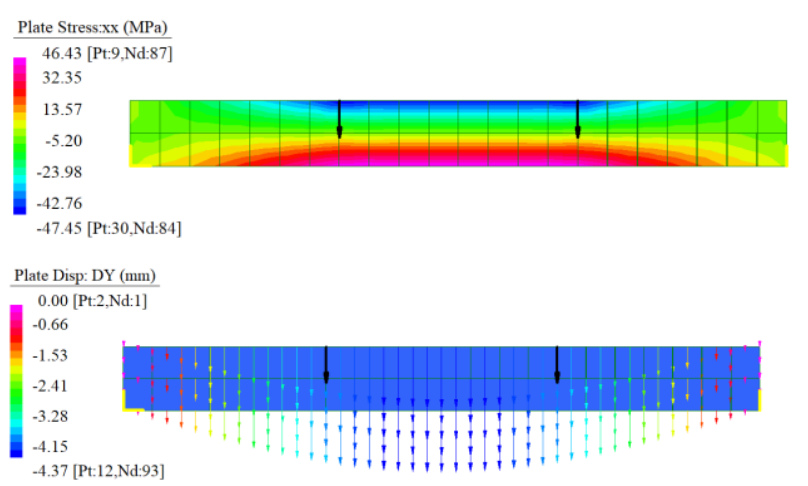

b)

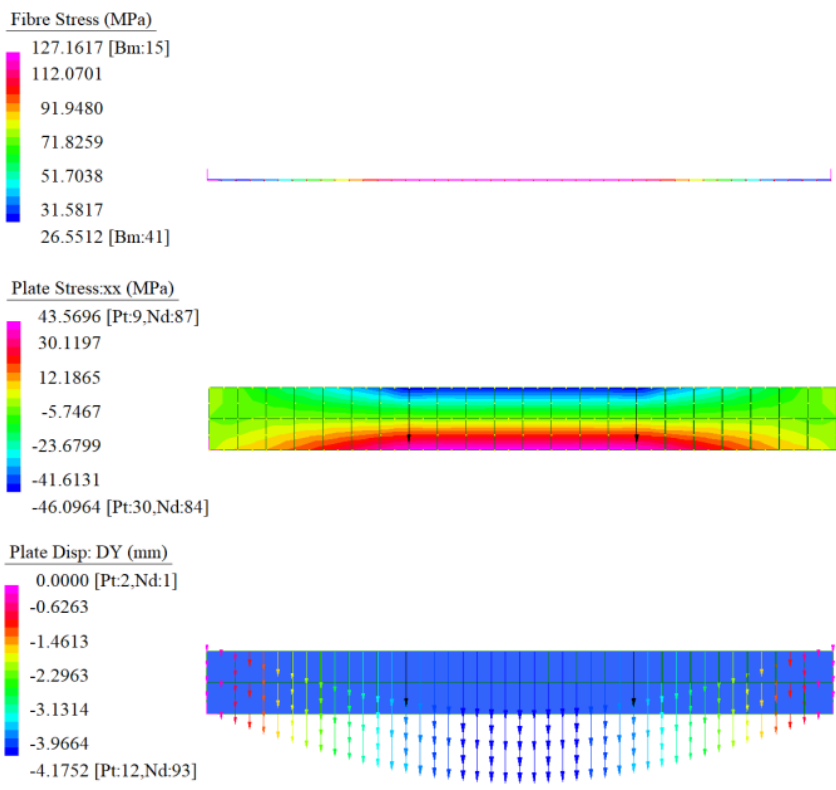

Fig. 4: Stress and displacement distribution in (a) the un-reinforced glass beam and (b) CFRP-reinforced glass beam.

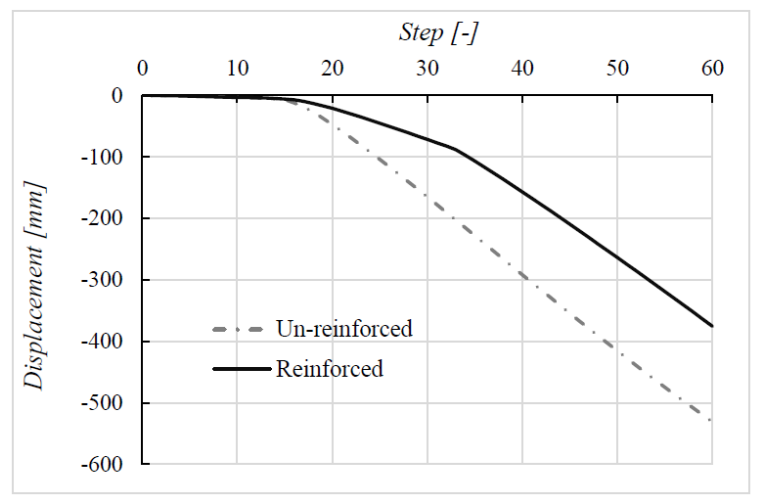

Fig. 5: Displacement curves for the un-reinforced and reinforced glass beams.

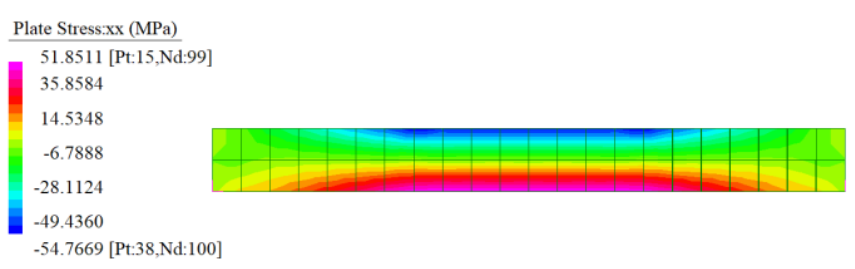

Fig. 6: Non-linear analysis: xx-stress distribution (Step 13).
In Figure 7 the stress-strain curves for the specimens (i.e. un-reinforced and reinforced glass sheet) are represented. It is possible to notice that after $50 \mathrm{MPa}$ (corresponding to step 13), the stress-strain curve shows a jump and the behaviour of the two sheets is not the same anymore. In the case of reinforced sheet, a different behaviour in terms of glass stresses was observed respect to the un-reinforced sheet. Furthermore, a significant difference has been detected in terms of ultimate strain if compared to the columns with unreinforced sheet.

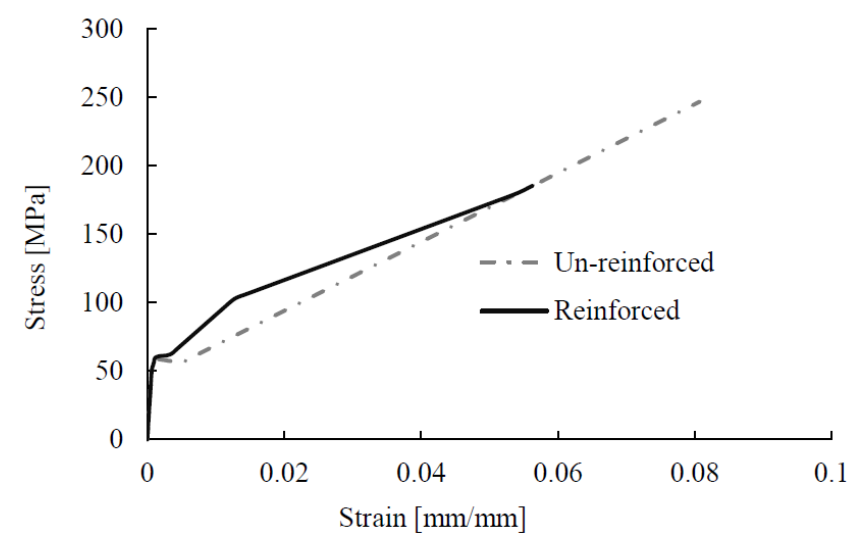

Fig. 7: Stress-strain curves for the un-reinforced and reinforced glass sheets.

Similarly to the laminated glass beam reinforced with CFRP-rod, a numerical analysis of a glass plate has been carried out. The load-pattern has been applied orthogonally to the plane, as shown in Figure 3a. In particular, the distributed load was applied at the third and at the two-third points of the plate. The FEM-analysis results show that the stress values of the plate were lower than the ultimate compressive and tensile strength (Figure 8).
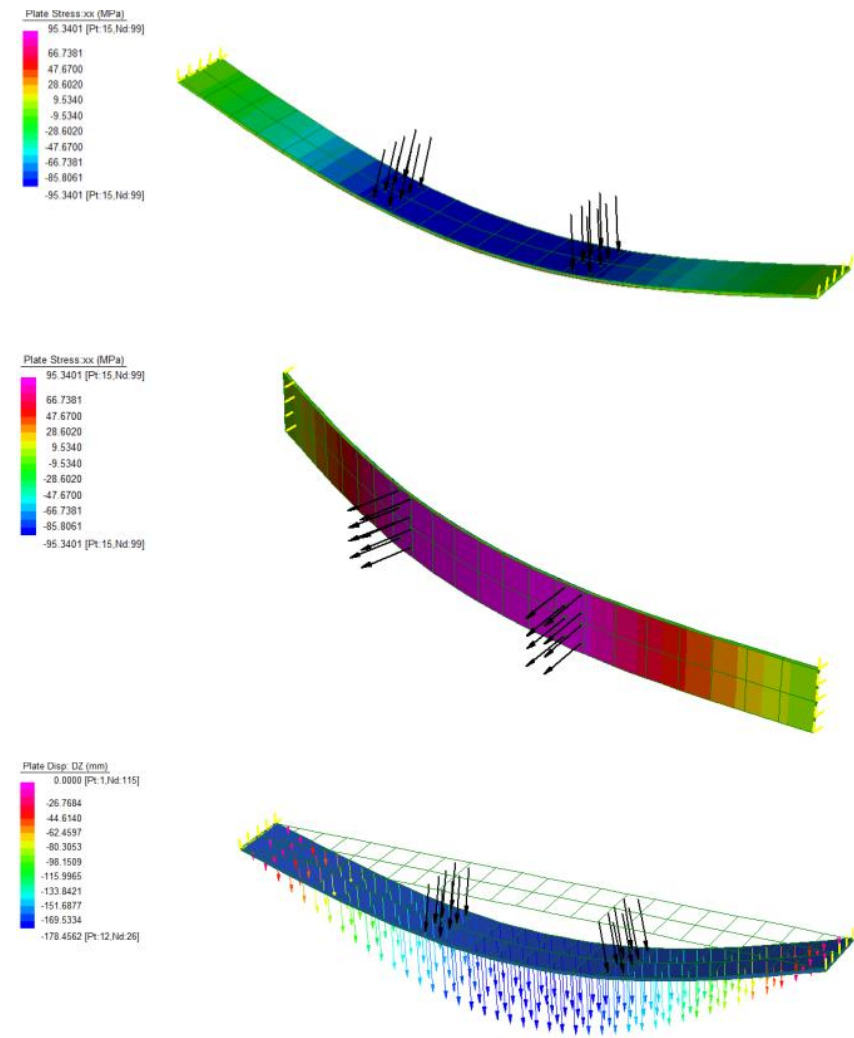

Fig. 8: Results of the FEM analysis on the glass plate without holes. 
The glass plate has been then modelled with two circular holes. In this case, a vertical displacement has been applied at the third and at the two-third points of the span. Unlike in previous case, in the glass plate with the holes the stresses in the area around the holes are greater than the ultimate tensile strength of glass (Figure 9). Therefore, the presence of two holes varies significantly the structural response of the glass plate. The area around the hole can be affected by failure mechanism.

Therefore, a deeper analysis of the stresses in the area around the holes is always required.
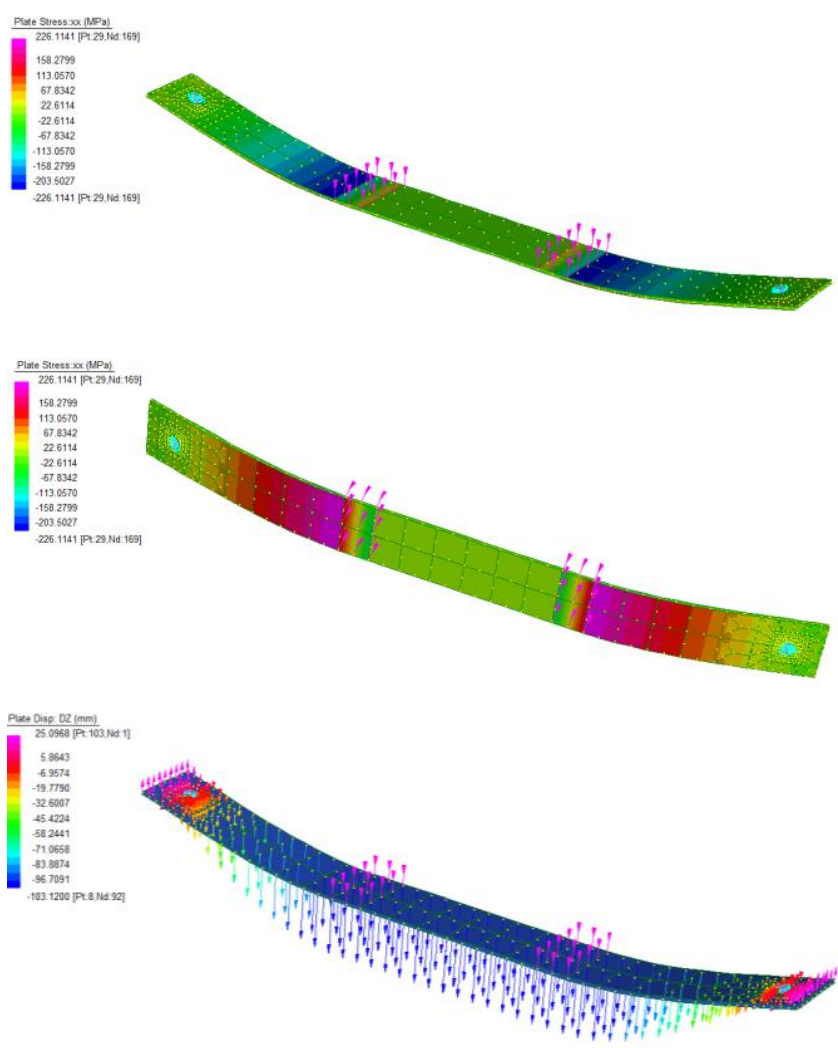

Fig. 9: Results of the FEM analysis on the glass plate with holes.

\section{CONCLUSIONS}

The numerical analysis carried out in the present research wants to highlight that the brittleness of the glass is a fundamental characteristic for the design of structural glass elements. To overcome this gap, in the modern design, alongside techniques such as stratification of the glass, design criteria such as fail-safe design have been introduced too, which allowed the use of glass in big and relevant architectural structures. In this scenario, a possible solution is proposed in this paper. It consists in the use of CFRP-glass composite structures by combining a brittle material (i.e. glass) with another material that offers ductility to the system (i.e. CFRP-rod). In particular, it is proposed to use embedded carbon fibre reinforced rod at the bottom face of structural glass beams. Such technique results very promising because it can provide a transparent and yet ductile structural element with a safe failure mode. The behaviour of an ordinary glass beam has been compared to a beam reinforced with CFRPbar. From the FEM-analyses conducted for two types of beam investigated it appeared that the for the sample with embedded reinforcement (CFRP-rod) the stress level and the displacement of the glass sheet have been decreased.

Additionally, the influence of the holes on the glass plate was studied. In particular, a comparison between the glass plate without and with holes was conducted. Commonly, in the structural applications it is need to perforate the glass plate. The hole, in fact, are elements that allow the connection of the plate with other structural components. The conducted study show that the presence of the holes make particularly brittle the glass area around the holes.

Because of the complexity of the topic, the present investigation is still in the stage of qualitative analysis. In order to obtained an extensive analysis, there are many aspects needed be assessed to prove, such as the more accurate physical properties of PVB, the parameters of glass and the geometric factors (i.e. beam size and hole size), influence in significantly the structural response.

\section{ACKNOWLEDGMENT}

Dora Foti as Principal Investigator of the project "Mitigating the impacts of natural hazards on cultural heritage sites, structures and artefacts (MICHe)" acknowledges the Italian Ministry of Education, University and Research for support under a Project of Relevant National Interest PRIN 2015.

\section{REFERENCES}

[1] W. L. Beason, J. R. Morgan, "Glass failure prediction model", J. Struct. Eng., vol. 110(2), 1984, pp 197-212,

[2] G. Savineau, F. Serruys, "Durability and postbreakage behaviour of laminated safety glass". In Glass Processing Days 2001 Conference Proceedings Book, June 2001, pp. 328-330.

[3] K. Martens, R. Caspeele, J. L. I. F. Belis, "Development of composite glass beams-A review", Eng. Struct., vol. 101, 2015, pp.1-15.

[4] E. Cagnacci, M. Orlando, P. Spinelli, "Experimental campaign and numerical simulation of the behavior of reinforced glass beams", Proc. of the Glass Performance Days-2009, Tamper, Finland, pp.12-15.

[5] A.B. Ølgaard, J.H. Nielsen, J.F. Olesen, "Design of mechanically reinforced glass beams: modelling and experiments", Structural Eng. Int., vol. 19(2), 2009, pp.130-136.

[6] C. Louter, J. Belis, F. Veer, J.P. Lebet, "Structural response of SGlaminated reinforced glass beams; experimental investigations on the effects of glass type, reinforcement percentage and beam size", Eng. Struct., vol. 36, 2012, pp. 292-301.

[7] M. Slivanský, "Theoretical verification of the reinforced glass beams", Procedia Eng., vol. 40, 2012, pp. 417-422.

[8] C. Bedon, C. Louter, "Exploratory numerical analysis of SGlaminated reinforced glass beam experiments", Eng. Struct., vol. 75, 2014, pp. 457-468.

[9] F. Bernard, L. Daudeville, "Point fixings in annealed and tempered glass structures: Modeling and optimization of bolted connections", Eng. Struct., vol. 31(4), 2009, pp. 946-955.

[10] N. Pourmoghaddam, J. Schneider, "Finite-element analysis of the residual stresses in tempered glass plates with holes or cutouts", Glass Struct. \& Eng., vol. 3(1), 2018, pp. 17-37.

[11] M. Timmel, S. Kolling, P. Osterrieder, P. \& Du Bois, "A finite element model for impact simulation with laminated glass", Int. J. of Impact Eng., vol. 34(8), 2007, pp. 1465-1478.

[12] L. Lani, "Comportamento meccanico di lastre inflesse in vetro stratificato rinforzate con cavi metallici pretesi", $\mathrm{Ph}$.D. Thesis, Corso di Dottorato in Ingegneria delle Strutture XVIII ciclo, University of Pisa, 2003. (in Italian)

\section{Creative Commons Attribution License 4.0 (Attribution 4.0 International, CC BY 4.0)}

This article is published under the terms of the Creative Commons Attribution License 4.0 https://creativecommons.org/licenses/by/4.0/deed.en US 